found considerable agreement between consultants and trainees on items concerning the structure and content of supervision, although a significant number of consultants and trainees were not fully satisfied with the level of individual supervision.

Although we agree with Azuonye's call for supervision to be given the high priority it deserves, we would like to suggest an alternative solution to his request for a Royal College of Psychiatrists' Special Task Force on Educational Supervision. It has previously been suggested that training schemes establish their own guidelines as to what constitutes good training and that trainees take a lead in auditing practice against these guidelines (Davies, 1993). Our project provided the basis for such a practice on the UMDS training scheme. Consultants and trainees are able to make significant improvements at a local level in the absence or anticipation of more explicit guidelines from the College. Such an approach allows the trainee and consultant to agree upon the content of supervision, and allows for the fact that some consultants may have special expertise in some areas and less knowledge in others. A centrally led dictate on supervision could be hard to implement effectively and maybe unsuited to the diversity of services, trainees and consultants.

Davies S. (1993) Consumer audit of psychiatric training. Psychiatric Bulletin, 17, 503-504.

HerRIOT, P., BHUI, K. \& LELLOTT, P. (1994) Supervision of trainees. Psychiatric Bulletin, 18. 474-476.

PETER M. HERRIOT, Noarlunga Health Services, Noarlunga Centre, South Australia 5168; KAMALDEEP BHUI, Institute of Psychiatry, London

\section{Core psychiatry for tomorrow's doctors}

Sir: The College Working Party's report on core learning in undergraduate psychiatry (Psychiatric Bulletin. August 1997, 21, 522-524) mirrors changes already taking place in medical schools throughout the UK. In Nottingham a set of learning objectives, very similar to that proposed by the working party, was devised (Cantwell \& Brewin, 1995). The list differs mainly in the realm of attitudes, an area which caused us the greatest difficulty. Unending suggestions for inclusion could be made in a discipline which students are likely to approach with a mix of attitudes based on lay misconceptions and fears. Like the working party we addressed issues about stigma, the multi-disciplinary team and the interplay between psychological and physical factors. Two other areas stood out in relation to controversies over psychiatric practice and the particular importance of the doctor-patient relationship in psychiatry. Our list is given below. (A complete list of all learning objectives given to Nottingham psychiatry undergraduates is available from the authors.)

Learning objectives, attitudes:

(a) appreciate the inter-relationship between physical and psychological symptoms and the need to be aware of psychological factors in all medical conditions:

(b) recognise the stigmatisation associated with mental illness and learning difficulties and how this can affect patients and their families;

(c) be aware of the ethical dilemmas and controversies involved in the diagnosis and management of mental disorder;

(d) appreciate the function of the multi-disciplinary team and the role of each of its members:

(e) as you progress through your attachment. acknowledge the importance of the therapeutic relationship between doctor and patient and how the time scale for change is lengthened in psychiatry.

The need to challenge perceptions of psychiatry is undeniable, and the devising of objectives relatively straightforward. We have no easy answers, however, on how such attitudinal change can be brought about in new curricula.

CANTWELL. R. \& BREWIN. J. (1995) The new undergraduate curriculum: implementing the changes in Nottingham. Psychiatric Bulletin. 19. 482-484.

Roch CANTwell, Consultant Psychiatrist and Honorary Clinical Senior Lecturer, University Department of Psychological Medicine, Gartnavel Royal Hospital, 1055 Great Western Road. Glasgow G12 OXH; and JOHN BREWIN, Consultant Psychiatrist, Department of Psychiatry, B Floor, South Block, Queen's Medical Centre, Nottingham NG7 2UH

\section{Community psychiatry in the RAF: an evaluative review}

Sir: Julian Hughes is to be congratulated on using an audit of his first six months' experience of providing community services in the Royal Air Force (RAF) to produce a provocative and thoughtful paper (Psychiatric Bulletin. July 1997, 21, 418-421). However, there are two omissions of pertinent fact. Most significantly, at the time of his audit the RAF was in the middle of major changes, almost halving its manpower. Many were facing redundancy. Given this very high level of social change, the finding of an unusually high referral rate for adjustment disorder is not too surprising and caution should 
be exercised in drawing wider conclusions on the general pattern of psychiatric morbidity in the Services.

Second, the RAF's medical services were themselves in the process of major change. The future provision of medical services has been addressed in the Defence Costs Study that closed the RAF psychiatric centre. The resulting turmoil would have disrupted the normal functioning of the Community Department. Again, it is appropriate to exercise some caution on the conclusions to be drawn.

The RAF community psychiatric teams provide a primary care liaison psychiatric service. Audit has shown them to be both effective and efficient, they enjoy the strong support of the RAF medical executive. Service medical officers make direct referrals, either to the community psychiatric nurse or to the psychiatrist. The team is closely integrated and community psychiatric nurses refer to the psychiatrist for diagnostic, managerial or administrative decisions. Communication plays an important role in its successful functioning and the psychiatrist has an important supervisory role. It would have been of great interest to have a view of these diagnostic, managerial, educational and supervisory aspects.

Hughes correctly identifies occupational issues as of major concern to the Services. The occupational role of military psychiatry is the reason for its existence. The number of uniformed psychiatric personnel is determined by the requirements of the war role; in operations RAF psychiatric personnel deploy to form psychiatric support teams. Peacetime care is provided from within these resources. Psychiatric services are no longer available to dependants and our civilian colleagues will indeed need to become more aware of the special circumstances of the Services.

G. E. REID, Consultant Adviser in Psychiatry (RAF), Royal Air Force Brize Norton, Oxford OX18 3LX

\section{The role of research in psychiatric training: the trainees' perspective}

Sir: I read the Collegiate Trainees' Committee comment on the use of logbooks in training (Psychiatric Bulletin, May 1997, 21, 278-280) with a sense of déjà $v u$. In the article they state that trainees should be permitted to develop skills in management or teaching as an alternative to research, given that ". . . not all trainees are interested in, or successful at, research."

In 1995 I was invited to conduct a study of trainees' attitudes to research in south-west Thames, as chair of the trainees' committee. A high response rate was obtained $(68 \%, n=122)$, as compared to previous studies (Hollyman \&
Abou-Saleh, 1985; Junaid \& Daly, 1991). Fifty per cent of registrars and $21 \%$ of senior house officers (SHOs) had conducted some form of research. The most notable finding was an inverse relationship between enthusiasm for research and training experience. Eighty per cent of registrars and $100 \%$ of SHOs believed research was important for a career in psychiatry, while only $52 \%$ of registrars and $67 \%$ of SHOs believed it should be important. The latter correlated in inverse proportion to the length of time in training.

Crisp (1990) has argued that all psychiatric trainees would benefit from research experience. in order to develop "a capacity to think systematically, measure comprehensively and accurately and analyse the information". Alternatively it could be argued that formal research should not be imposed on the majority. In keeping with the Nietzschean spirit of National Health Service reforms, research could focus on a potential academic elite, improving quality at the expense of quantity. This would also remove the unnecessary burden of 'publish or be damned' from the ranks of disinterested trainees.

CRISP. A. H. (1990) The case for teaching and research experience and education within basic specialist training (registrar grade) in psychiatry. Psychiatric Bulletin, 14, 163-168.

Hollyman, J. A. \& ABOU-SAlEH, M. T. (1985) Trainees and research. Bulletin of the Royal College of Psychiatrists. 9. 203-204.

JUNAID. O. \& DALY, R. (1991) An audit of research activity among trainee psychiatrists. Psychiatric Bulletin. 15. 353-354.

JOHN FARNILl MORGAN, Clinical Research Fellow and Honorary Senior Registrar, St George's Hospital Medical School, Tooting, SW17 ORE

\section{Stalking the stalkers}

Sir: From the 16th June 1997 the United Kingdom has come in line with other countries by introducing the Protection from Harassment Act 1997 to combat stalking. This allows a court to order imprisonment or a fine and allows for the rewarding of damages for "anxiety and any financial loss resulting from harassment".

The behaviour of stalkers is generally traumatic for their victims and a recent study shows that a considerable percentage have been forced to change their lifestyle, move accommodation up to five times, change employment, curtail their social outings and remain in a state of siege in their homes. A preponderance of victims report deterioration in their physical and/or mental health since the onset of their ordeal which may have lasted for as long as 20 years. The stalkers may resort to violence, damage property or possessions of their victim, and 